an unconscious murderer of little children. Greater criminality than this can no man possess : that he jeopardize the lives of his kind for the sake of money. In no profession is there greater need for self-control and the exercise of the strictest honesty and personal integrity.

The conservation of our domesticated animals and their products is of the highest importance to the welfare of our nation. The following figures are taken from the census of 1910. They are the latest official figures available, although probably inaccurate at the present time. During the last five years there has probably been an increase in the number of veterinarians. In this period, also, there has probably been a decrease in the number of some of the domesticated animals because of the ravages of foot and mouth disease and established diseases as well as a decline, more or less fluctuating, in production.

The figures show that in 1910 there were in this country on farms and not on farms 206,646,069 domesticated animals, including cattle, horses, mules, asses, burros, swine, sheep, and goats, with a valuation of $\$ 5,296,421,619$. With 11,652 veterinarians in this country, we have a ratio of one veterinarian to 17,734 animals, or in financial terms one veterinarian to $\$ 454,550$ of animal valuation. While this average is higher in some parts and much less in others, it serves to emphasize the fact that a great responsibility rests upon the veterinarian if he is to assist, not merely in the conservation of much valuable animal stock already in existence, but in promoting a still greater production. The necessity for this is obvious in the case of the animals used for food. The census returns show a decrease of 8.7 per cent. in the number of cattle on farms with an increase of $1.6 \mathrm{per}$ cent. in their valuation; a decrease of 7.4 per cent. in swine with an increase of 72.1 per cent. in their valuation, and a decrease of 14.7 per cent. in sheep with an increase of 36.8 per cent. in their valuation. Horses, mules, asses and burros have increased in number during this period and their valuation shows a much higher percentage of increase than in the case of the food animals.

It has been figured that our average disease loss of live stock in the United States is $\$ 150,000,000$ and our exposure loss $\$ 44,000,000$, a total of nearly $\$ 200$,000,000 annually. It is evident that few industries could endure such proportionate losses and survive. The largest toll has been taken from the food-producing animals. We may assume that practically all losses from exposure are preventable and that this item will diminish as the open-range boundaries contract and better provision is made for the winter sustenance of stock.

The checking of the disease loss is a slower and more serious matter and it is here that the services of the veterinarian are necessary. To meet this obligation he must be something more than an uneducated, practical horse doctor more or less successful in the treatment of spavins, ringbones, colics and other routine cases of practise. He must be able to see beyond the educational horizon which treats only of routine practise and, with a proper blending of scientific and practical training, show an appreciation not only of personal but community interest in the animal resources of our country.

Pierre A. Fish

ITHACA, N. Y.

\section{QUANTITY AND QUALITY}

Professor ÉmIL Borel, who visited America in 1912 as one of the inaugural lecturers at the opening of the Rice Institute of Houston, Texas, recently embodied some of his impressions about America in an article under the 
above title, published in the April, 1915, number of the Revue du Mois. As this article was written by a Frenchman after the beginning of the great European War, it has naturally been very much influenced by feelings aroused by events connected with this war.

The central thought of the article is that there is a great tendency to lay too much stress on quantity and too little on quality in speaking about scientific achievements. It is perhaps natural, under the conditions existing while the article was written, that the author concluded that the Germans had done most during the last forty years to acclimatize in Europe the conception which makes quantity the sole criterion for the social, intellectual and moral values of the people. Many American readers may however regret to find that this conception is said to be of American origin, even if this statement is modified by the fact that the most cultured Americans are striving to habituate their countrymen to judgments based on quality.

Among the illustrations given by Professor Borel in support of his contention that the Germans have in recent years unduly emphasized quantity is the following small table, which aims to give the approximate number of letters in an average volume of certain important mathematical periodicals:

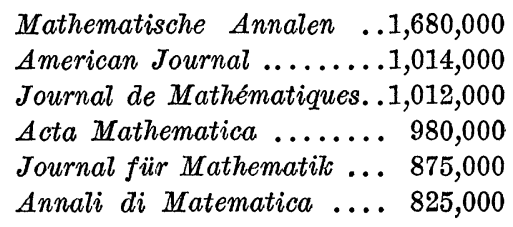

This table was first published at the end of the "Generalregister" to the first fifty volumes of the Mathematische Annalen. About two years after its publication the Transactions of the American Mathematical Society began to appear in volumes involving a much larger number of letters than the American Journal, which occupies the second place in the given list. While it may be questioned whether it is desirable to direct special attention to the mere size of the volumes of a periodical the given table has at least an indirect value, since it furnishes an interesting concrete illustration of the meaning of a million.

As questions relating to quantity are much more easily treated by statistical methods than those relating to quality, the growing popularity of statistical methods, even in educational matters, seems to be a sign that we are at present placing too much emphasis on quantity at the expense of quality. Mental inertness naturally leads to considerations of quantity rather than of quality. It is much easier to enumerate the books and articles written by a certain man than to exhibit the value and influence of these publications. It is easier to estimate a man's wealth in dollars than to determine the merits of his intellectual contributions or his moral influence on his fellows. It is easier to give the number of students at a university and the size of the budget than to estimate the value of the work done at the institution.

In view of the fact that questions of quantity are usually much easier than those relating to quality, it is perhaps the more surprising to find that Professor Borel attributes to America the origin of the conception which makes quantity the unique criterion for social, intellectual and moral values of the people. If this criticism is not deserved it should certainly not pass unanswered, for the implications which it involves are fundamental and far-reaching. The fact that the criticism was made by a man of very high scientific standing, who recently spent some time in our midst and in company with some of our leading men, makes it all the more noteworthy.

It is perhaps especially interesting that the tendency to make quantity the sole criterion for intellectual values should be regarded as being of American origin. Intellectual leadership even along somewhat baneful lines implies vigorous intellectual life, and it is of some interest to find that we are credited with such life by a competent observer. As Professor Borel is a mathematician it would appear probable that his conclusions in regard to the intellectual activities of a people would be largely influenced by their mathematical productiveness. It can, however, not be said 
that the quantity of mathematical output on the part of the Americans is, or has ever been, such as to justify the statement that the conception of making quantity the sole criterion in regard to mathematical activity originated with us. As regards quantity we never had any mathematical writer who could be compared with Euler, Cauchy, or Cayley.

It is true that in recent years the quantity of American mathematical literature has increased rapidly, but the same is true in regard to this literature in several other countries. As evidence of the fact that the United States is not inclined even at the present time, to go to excess in regard to the quantity of its mathematical literature we refer to the recent publications under the general direction of the International Commission on the Teaching of Mathematics. At the Paris Conference held in April, 1914, the extent of these publications reported by various countries was as follows:

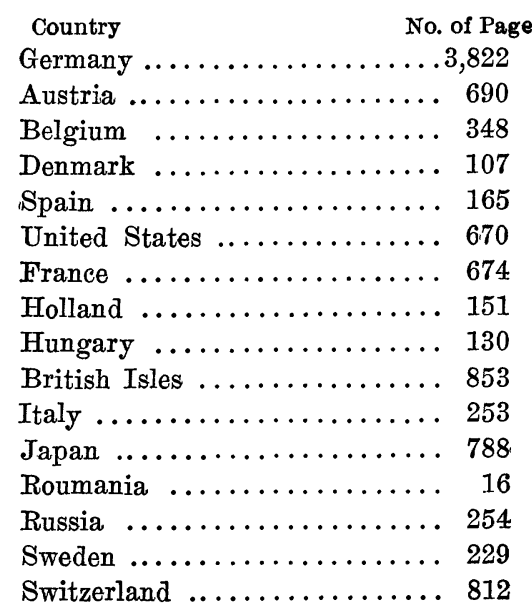

As questions relating to teaching offer unusual opportunities for extensive publications the above table is very instructive as regards tendencies towards quantity along mathematical lines. It seems therefore unlikely that Professor Borel had mathematics in mind when he referred to our undue emphasis on quantity. It is much more likely that he was impressed by the fact that our conversation and our newspapers are so largely confined to questions of quantity. In a comparatively new country the changes as regard quantity are so rapid as to attract wide attention, and these changes furnish the easiest topics of conversation. Changes as regards quality may be no less rapid but they furnish less harmless subjects of conversation in view of inherent difficulties and room for differences of opinion.

It is perhaps unfortunate that our conversation even in regard to intellectual matters is so commonly directed by a desire to offend no one instead of by a desire to call attention to what is very important. The thoughtful foreigner who comes into our midst is thus naturally impressed by the fact that we so commonly speak of harmless quantity instead of the more important quality. Some years ago while talking with a great French mathematician I was much impressed by the fact that, in speaking about two of his eminent colleagues, he was very free in saying which of the two he regarded as the more eminent. I felt then that in America I would probably not have found such voluntary reference to such a delicate matter.

The seriousness of this question becomes apparent if it is observed that the tendency to refrain from referring to quality in a public way is reflected to some extent in the life of the people. If in a university community, for instance, it is regarded as undesirable to refer to the quality of the work of the various mem. bers of the faculty, and if the quantity of salary is the sole index of relative standing, there is apt to be little effort on the part of the younger men to attain to a greater degree of efficiency. Many questions of quality appear shocking only in view of their newness. After they have passed into the stream of allowable conversation topics they are not likely to offend anyone and they often serve a useful purpose. In fact, the inefficiency of a university professor often becomes a perfectly harmless topic. The danger lies in the early stages towards such publicity as regards the true conditions, and it is here where there is usually the greatest field of usefulness.

The greatness of a nation in the intellectual and moral life is largely influenced by its emphasis on quality. Professor Borel urges that 
it is the duty of France to restore the preëminence of quality and he points out that the way towards this end is easy. In fact his suggestions are "to give to quality opportunity to manifest itself, do not hide it under a bushel, for men never refuse to recognize the intellectual or moral superiority which is pointed out to them; their natural sentiments of equality and justice, far from being shocked by this, are exalted thereby. The young people, in particular, regard themselves united with the comrade whom they have learnt to appreciate; far from being jealous of his success, they are happy with him."

These suggestions should be equally useful among us where the need of reform is even more evident than in France. Our great western state universities are doubtless especially in danger of being overwhelmed by judgments of quantity, in view of their very direct contact with the public. They present therefore unusually important centers for emphasis on quality, and for guarding against being absorbed in the work which admits of exhibition in attractive circulars presenting statistical data in regard to quantity. Public references to quality of work and to the deeper joys and compensations of intellectual life are especially needed in these institutions.

The very rapid growth of our educational institutions has naturally led to an abnormal interest in changes in quantity. It is so easy and harmless to speak of the increase in the material equipment. It is much more difficult and delicate to make clear that the intellectual advances made by the faculty have kept pace with these material advances, or that the moral and intellectual influences surrounding the students are better than they were in former years. These latter questions involve comparisons, and they frequently lead at first to differences of opinion. They are, however, the more important, and the foreign scholars who may be in our midst will judge us very largely by the way we deal with these questions of quality. It will be very unfortunate if we continue to impress these men as we seem to have impressed Professor Borel, especially since such impressions seem to represent only our superficial attitude, at least, as far as they relate to our intellectual and moral life.

G. A. MILLER

UNIVERSITY OF ILLINOIS

\section{FREDERIC WARD PUTNAM}

With Professor Putnam, who died on August 14, at the age of seventy-six years, the last of the three men has passed away who may well be called the founders of modern anthropology in America: Brinton, Powell and Putnam. Brinton in Philadelphia, with keen, analytic mind, full of imagination, with wide interests, opened up ever new fields and problems and stimulated through his personal influence the work of others and paved the way to the recognition of anthropology as a scientific study. Powell performed the great service of organizing the anthropological work of the government by founding the Bureau of Ethnology and providing in this manner the means for scientific research. With rare insight he selected an unusually gifted group of men around himself, and to their labors we owe the fundamental data on which modern American ethnology has been built up. Through the sheer force of his personality he impressed some of his fundamental philosophic views and some of his methods upon his collaborators not only in the Bureau of Ethnology, but in a much wider group of scientists that came under his influence, and gave in this manner to anthropological studies a definite direction that may still be recognized.

Professor Putnam's contributions were of another kind. Taught in the Agassiz school of independent search for facts, he took up anthropological studies with that enthusiastic worship of material data as the indispensable basis for inductive studies that has dominated his life and that, together with his skill as an organizer, have made him the most potent factor in the development of anthropological institutions all over the country. Owing to the trend of his mind, his interests centered in the objective, tangible sides of anthropology and, therefore, his chief contribution lies in the development of museum work. The search for well authenticated Indian material and his in- 